\title{
Study on the Construction of the Performance Evaluation Index System of Fiscal Expenditure in China
}

\author{
Zhe Sun ${ }^{1}$, Ke Gao ${ }^{1,2}$ \\ ${ }^{1}$ The School of Public Finance and Taxation, Central University of Finance and Economics, Beijing, P. R. China \\ ${ }^{2}$ Development Research Center of Shandong Provincial People's Government, Jinan, P. R. China \\ Email address: \\ szsz1989@126.com (Zhe Sun),gkfly@126.com (Ke Gao)
}

\section{To cite this article:}

Zhe Sun, Ke Gao. Study on the Construction of the Performance Evaluation Index System of Fiscal Expenditure in China. International Journal of Economics, Finance and Management Sciences. Vol. 6, No. 3, 2018, pp. 82-86. doi: 10.11648/j.ijefm.20180603.12

Received: May 18, 2018; Accepted: May 21, 2018; Published: May 28, 2018

\begin{abstract}
The Nineteenth National Congress of the Communist Party of China put forward the full implementation of performance management. Thus, the importance of fiscal performance evaluation has risen to a new height. The performance evaluation index of fiscal expenditure is an important prerequisite for performance management. The performance evaluation index of fiscal expenditure policy refers to the assessment tool to measure the degree of achievement of fiscal expenditure policy performance goals. This paper study the performance evaluation indexes of fiscal expenditure policy from its basic framework and basic principles, categorization the indicators of fiscal expenditure performance evaluation system; make the evaluation of performance of fiscal expenditure more clearly. The construction of the performance evaluation index system of fiscal expenditure plays a very important role in evaluating the economy, efficiency and effectiveness of fiscal expenditure.
\end{abstract}

Keywords: Performance Evaluation, Index, Fiscal Expenditure

\section{Introduction}

The Nineteenth National Congress of the Communist Party of China put forward the full implementation of performance management. Thus, the importance of fiscal performance evaluation has risen to a new height. From the perspective of fiscal budget system, it is proposed that the implementation of performance management in a comprehensive way is a new path for the modernization of national governance and the innovation of government management (Zheng \& Wang [1], 2018). The performance evaluation index of fiscal expenditure is an important prerequisite for performance management.

The performance evaluation index of fiscal expenditure policy refers to the assessment tool to measure the degree of achievement of fiscal expenditure policy performance goals. It is a specific quantity reflecting the necessity, feasibility, process monitoring and overall effect of budget implementation. It has the effectiveness of measuring, monitoring and evaluating the degree of implementation of the policy and the economy, efficiency and effectiveness of budget management, and reveals the effectiveness of problems in policy implementation and budget management.
The performance evaluation index system of fiscal expenditure policy is based on the requirements of policy performance management evaluation and according to certain principles to reflect the contents of different policies and budgets and reflect the performance of evaluation objects.

Researches on fiscal performance indicators are comprehensively. Xiong [2] (2018) review the history of China's performance evaluation from a historical perspective. Some scholarsresearch the construction and improvement of performance evaluation index system for fiscal expenditure (Cheng \& Xue [3], 2015; Wu [4], 2015; Liu [5], 2016; Wang [6], 2017; Liu [7], 2017; Li \& Wang [8], 2018; Liu [9], 2018). Meanwhile, some others scholars have researched the target setting of fiscal performance evaluation (Wu [10], 2017; Wang [11], 2017). Zheng \& liao [12] (2017) study the fiscal performance evaluation from its concept, system and practice. Wang [13] (2018) establishes a three level framework for performance evaluation. And Ren [14] (2017) researches the individualized performance index design of fiscal funds.

On the basis of the above research, this study probes into performance evaluation index system of fiscal expenditure policy in China. 


\section{The Basic Framework}

The guideline of the design of the performance evaluation index system of fiscal expenditure policy is based on the requirements of national laws and regulations, the overall planning of national economic and social development, and the national industry planning. It should be given full consideration to the relationship between the development of policies and sectors and the coordinated development of economy and society, and policy implementation industry or department internal coordination as well as basic expenditure and project expenditure development level, mainly around the implementation of the comprehensive evaluation of the strategic objectives and functions of the policy. The performance evaluation index system of fiscal expenditure policy includes: The setting of the goal of policy performance; Investment and use of policy funds(the use of budgetary funds, the legality and compliance of expenditures, the financial management and asset allocation and utilization in order to achieve performance objectives); The system and measures adopted to achieve the goal of policy performance; The degree of completion and effect of policy performance goals(The achievement of performance objectives and the economic, social and ecological benefits of fiscal expenditure); Other content of policy performance evaluation.

First, according to the contents and requirements of the evaluation and the scope of application of indicators, it can be divided into common indicators and individual indicators. Common indicators: Common indicators are indicators applicable to all sectors and departments to evaluate policies and targets. It's generally determined by the financial department. It involves the necessity and feasibility of policy implementation, budgeting and implementation, financial management, asset allocation, use and disposal. Generally speaking, the common indicators are predominant control conditions to ensure that all expenditure policies, industries or departments and budgetary units' budgeting centered on performance, are universality. Individual indicators: Individual indicators are determined according to the characteristics of industries or departments that implement policies, and are applicable to different industries or departments. The personality index is formulated by the finance department in conjunction with the policy implementation department according to the performance target of the evaluated object.

Second, according to whether indicators can be quantified, they can be divided into quantitative indicators and qualitative indicators. Quantitative indicators: The quantitative index refers to the index that can directly evaluate through the data and reflect the evaluation results in quantity. Qualitative indicators: Qualitative indicators mean that it is difficult to directly analyze evaluation content and reflecting the object of evaluation through data calculation, which need to objectively describe and analyze the evaluation objects to reflect the evaluation results. Quantitative indicators and qualitative indicators are included in common indicators and individual indicators, which is a manifestation of whether common indicators and individual indicators can be quantified. The design of indicators system is usually based on common indicators, supplemented by individual indicators.

Third, according to the policy performance evaluation management process, the policy performance evaluation index system can be divided into the pre event performance index system, the event performance index system and the ex post performance index system.

\subsection{The Classification of the Pre Evaluation Index of Fiscal Performance}

According to the characteristics of pre performance evaluation of fiscal expenditure policy, the evaluation indicators are divided into three categories: policy decision, policy implementation, and policy performance. Policy decisions can be divided into five secondary level indicators: goal setting, decision-making process, policy establishment, policy decomposition, budgetary decision making (allocation of funds). The implementation of policies can be divided into three secondary level indicators: planning implementation, process control and management system. Policy performance can be divided into two secondary level indicators: output and outcome. A number of tri-grade indicators are set up under each secondary indicator. (Table 1).

Table 1. Preevaluation index system of fiscal expenditure policy performance.

\begin{tabular}{lll}
\hline First level indicator & Secondary level indicators & Weight (\%) \\
\hline & goal setting & 6 \\
Policy decision & decision-making process & 10 \\
& policy establishment & 10 \\
& policy decomposition & 6 \\
The implementation of policies & budgetary decision making (allocation of funds) \\
& planning implementation & 6 \\
Policy performance & process control & 6 \\
& management system & \\
\hline
\end{tabular}




\subsection{The Classification of Fiscal Expenditure Policy Event Performance Indicators}

The event performance evaluation of fiscal expenditure policy is the implementation evaluation in the process of policy implementation. Although the implementation of the policy at this time is not yet finish, the economy, efficiency and effectiveness of policy implementation have emerged. Especiallythe defects in policy options, problems in the allocation of policy resources, changes in certain conditions in the policy environment have been exposed. This evaluation can be used to adjust the policies inimplementing. However, the event evaluation of fiscal expenditure policy performance is just point at a certain process in the process of policy implementation, so it is transitional and temporary. According to the transitional and temporary nature of event performance evaluation in fiscal expenditure policy, theevent performance evaluation indicators of fiscal expenditure policy are divided into three categories: the guarantee of policy implementation, the effectiveness of policy implementation process control and the attainment of policy stage goal. (Table 2).

Table 2. Event evaluation index system of fiscal expenditure policy performance.

\begin{tabular}{lll}
\hline First level indicator & Secondary level indicators & Weight (\%) \\
\hline & the guarantee of system construction & 15 \\
The guarantee of Policy implementation & theguaranteeofInstitutional and staff & 10 \\
& the guarantee of operation mechanism & 10 \\
The effectiveness of Process control & time control of policy implementation & 8 \\
& program control of policy implementation & 9 \\
capital control of policy implementation & 9 \\
\hline
\end{tabular}

\subsection{The Classification of Ex Post Evaluation Index of Fiscal Performance}

According to the core content of the ex post evaluation of the performance of fiscal expenditure policy, the post evaluation index of fiscal expenditure policy performance is divided into five categories: relevanceof policy objective, efficiency of policy implementation, benefit of policy implementation, the fairness of policy and demonstration of policy. The relevance of policy objective evaluate the level of objective satisfaction brought about by policies itself, it is the evaluation of the usefulness of policies, as well as the evaluation of scientific of policy decisions. The efficiency of policy implementation aims to evaluate whether the policy implementation process is scientific and reasonable, it is the evaluation of the efficiency of financial management and the scientific management of financial funds. The benefit of policy implementation isthe evaluationof the effect of policy implementation; it evaluates the specific scope of the policy effect, the realization of the output target, the relevance with the policy objectives and the satisfaction of the social parties. The fairnessof policy concern the relationship between capital allocation and the universality of policies, it is a comprehensive consideration of public nature, non-difference and non-exclusiveness of public services. The demonstration of policy evaluates the future applicability of policy from the positive aspects and problems, it is a comprehensive evaluation of the effect of policy implementation, and has important reference value for future similar policy decisions. (Table 3).

Table 3. Expost evaluation index system of fiscal expenditure performance.

\begin{tabular}{|c|c|c|}
\hline First level indicator & Secondary level indicators & Weight $(\%)$ \\
\hline \multirow{3}{*}{ Relevance of policy objective } & level of Policy meets demand & 5 \\
\hline & the reasonableness of the decomposition of policy tasks & 5 \\
\hline & the degree of implementation of policy effect & 12 \\
\hline \multirow[b]{2}{*}{ Efficiency of policy implementation } & the scientificity of policy planning & 7 \\
\hline & effectiveness of policy process control & 8 \\
\hline \multirow{2}{*}{ Benefit of policy implementation } & effect of policy implementation & 20 \\
\hline & degree of satisfaction of policy implementation & 15 \\
\hline \multirow{2}{*}{ The fairness of policy } & the fairness of the allocation of policy funds & 5 \\
\hline & universality of policy & 5 \\
\hline \multirow[b]{2}{*}{ Demonstration of policy } & positive factors and effects of policy & 4 \\
\hline & the typicality of the problem of policy & 3 \\
\hline
\end{tabular}




\section{The Basic Principles}

\subsection{Principle of Objective Relevance}

The design of performance evaluation indicators of fiscal expenditure policy should be directly related to the performance objectives of policy implementation sectors or departments, should properly reflect the achievement degree of performance goal, can comprehensively and systematically reflect the characteristics of evaluation objects. Each of the indicators can be linked to each other, as well as comprehensively reflect the relationship, inner connection and regularity of the performance components of the policy implementation industry or department. The index system should be unified, and unified standard evaluation should be adopted for the same index.

\subsection{Comparability Principle}

The performance indicators of fiscal expenditure policy should be independent of each other at the same level. Not only does it reflect the commonality of the policy implementation industry or the department, but also should be comparable in different time, region, industry and department under the condition of the same nature and the performance evaluation index set for the same kind of evaluation objects.

\subsection{Objectivity Principle}

The indicator data selected in the performance evaluation index of fiscal expenditure policy should have a legitimate and accurate source; at the same time truly reflect the actual situation of the evaluation objects of the policy implementation industry or department.

\subsection{Practical Principle}

The selection of performance indicators for fiscal expenditure policy should focus on the combination of scientific and practicability. It not only accurately reflects the performance connotation of the policy implementation industry or department, but also considers the practical feasibility and application cost of the indicator. It should pay attention to the combination of comprehensiveness and simplicity, fully reflect the performance of fiscal expenditure, and highlight key performance.

\subsection{Principle of Management Effectiveness}

Management effectiveness is the policy implementation capacity and policy management efficiency of the policy implementation industry or department in achieving policy objectives. The design of performance evaluation index of fiscal expenditure policy should fully reflect the management effectiveness of the policy implementation industry or department.

\subsection{Principle of Dynamic and Extensibility}

The determination of the performance evaluation index of the policy implementation industry or department is not only restricted by the regulation of its industry or department and the law of its own development, but also changes with the changes of many factors such as the external economy, politics, culture and the needs of the people. Therefore, the policy performance evaluation index system is dynamic and extensible. Thefiscal departments and policy implementation sectors or departments can continuously improve the indicators according to the performance evaluation work.

\section{Conclusion}

The construction of the performance evaluation index system of fiscal expenditure plays anextremely important role in evaluating the economy, efficiency and effectiveness of fiscal expenditure. Through this study, we categorization the indicators of fiscal expenditure performance evaluation system, make the evaluation of performance of fiscal expendituremore clearly. Meanwhile, the subsequent application of the results of fiscal expenditure performance evaluation also plays an important role in practical work. In further study, we can also learn from Swedish experiences that improve fiscal performance through improve and perfect planning stage and the implementation stage of the budget process [15].

\section{References}

[1] Zheng Fang-hui, Wang Yan-bing. Performance Evaluation of Fiscal Policy in the Context of Full Implementation of Performance Management [J]. Chinese Public Administration, 2018, 4: 19-26.

[2] Xiong Yan. Problems in the practice of fiscal expenditure performance evaluation and suggestions for improvement $[\mathrm{J}]$. Fiscal Supervision, 2018, 6: 5-9.

[3] Cheng Tao-lin, Xue Lei. Innovative suggestions on performance management of financial budget [J]. China State Finance, 2015, 6: 67.

[4] Wu yi. A preliminary study on the performance evaluation of fiscal expenditure [J]. Review of Economic Research, 2015, 70: $43-45$

[5] Liu Jian. Study on performance evaluation of fiscal funds [J]. Money China (Academic Edition), 2016, 19:2.

[6] Wang Kai. Design of Eco Fiscal Performance Evaluation System in Economic and Technological Development Zone [J]. China Management Informationization, 2017, 20 (23): 131-134.

[7] Liu Guo-yong. Exploration on the construction of fiscal performance evaluation index system [J]. China State Finance, 2017, 17: 19-21.

[8] Li Jin-shan, Wang Qian-qian. Views on the Performance System of Fiscal Expenditure [J]. Public Finance Research, 2018, 3:14-23. 
[9] Liu Hong. Research on design framework of financial expenditure project performance evaluation index system and its application [J]. Assets and Finances in Administration and Institution, 2018, 7: 20-21.

[10] Wu Hua-yang. Practical Analysis on Performance Indicators of Public Expenditure Performance Evaluation [J]. Modern Economic Information, 2017, 9: 68-69.

[11] Wang Jia. Study on Target Setting of Financial Performance [J]. Theory Monthly, 2017, 10: 141-145.

[12] Zheng Fang-hui, Liao Yi-er, Lu Yang-fan. Assessment of Fiscal performance: Concepts, systems and Practice [J]. Social Sciences in China, 2017, 4: 84-108+207-208.
[13] Wang Yong-jun. Establishing the three level framework and the best method for performance management [J]. New financial management (Government financial management), 2018, Z1: 20-21.

[14] Ren Xiao-Hui. Research on Individualized performance index design of Policy financial funds [J]. FiscalSupervision, 2017, 12: $62-64$

[15] Dietrichson, Jens; Ellegard, Lina Maria. Institutions Improving Fiscal Performance: Evidence from Swedish Municipalities [J]. International Tax and Public Finance, October 2015, v. 22, iss. 5, pp. 861-86. 